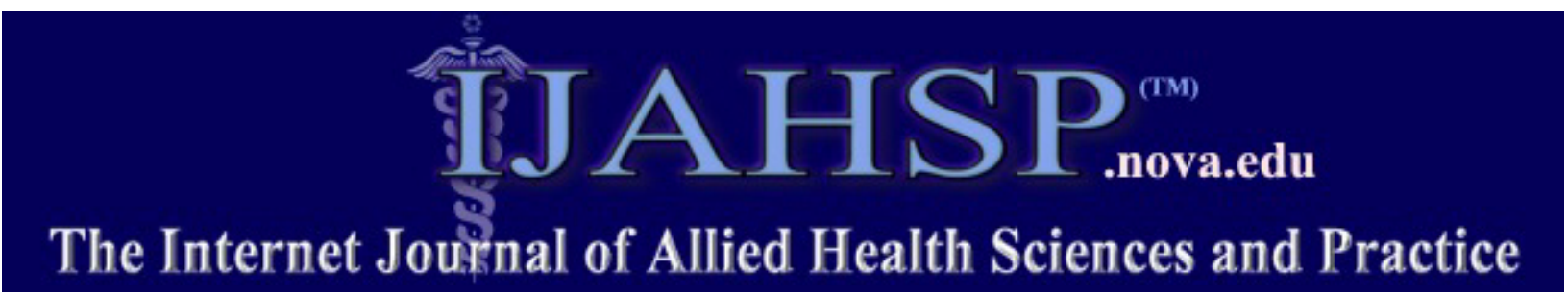

A Peer Reviewed Publication of the College of Health Care Sciences at Nova Southeastern University

Dedicated to allied health professional practice and education

http://ijahsp.nova.edu Vol. 10 No. 4 ISSN 1540-580X

\title{
An Exploration of Health Science and Nursing Students' Knowledge and Behaviors Related to Alcohol: A Preliminary Investigation
}

\author{
David M. Baker, PhD1 \\ Susan Stockton, $\mathrm{PhD}^{2}$
}

1. Assistant Professor of Hospitality, University of Central Missouri, Warrensburg, Missouri

2. Instructor of Health Education, University of Central Missouri, Warrensburg, Missouri

United States

CITATION: Baker DM, Stockton S. An Exploration of Health Science and Nursing Students' Knowledge and Behaviors Related to Alcohol: A Preliminary Investigation. The Internet Journal of Allied Health Sciences and Practice. Oct 2012. Volume 10 Number 4.

ABSTRACT

Purpose: To assess health science and nursing students' knowledge and behavior regarding drinking alcoholic beverages.

Method: A descriptive exploratory design with survey methodology was used to carry out the study. The participants were a convenient sample of 154 undergraduate health science and nursing majors enrolled in twelve Midwestern Universities. The Alcohol Questionnaire was used to elicit information from participants. The Pearson correlation coefficients were calculated using knowledge about alcoholic beverages with "How many standard drinks containing alcohol do you have on a typical day when drinking?"; "How often do you have a drink of alcohol beverage?"; and "How often do you have five or more drinks on one occasion." Results: The results respectively were $r=0.17, p=0.0167$, which implies that more knowledge was associated with more drinking; $r=-0.12, p=0.0125$, which implies that more knowledge was associated with drinking less often and $r=0.19$, $p=0.0125$, which implies that more knowledge was associated with excessive drinking. The correlation coefficients fell within the range -0.30 to +0.30 meaning that these were weak associations between knowledge of alcohol and drinking behavior. Discussion: The majority of respondents were generally very knowledgeable about alcohol but their behavior may be cause for concern because a third of the students binge drink. The pattern of behavior reported by this sample suggest a high-risk population who may not be aware of the health risks they are exposing themselves to through their excessive drinking behavior. Conclusion: The findings indicated that these students had good knowledge about alcohol but this knowledge was not associated with a lower likelihood of risky alcohol consumption. Binge drinking was common among $30 \%$ of the respondents. Healthcare professionals and educators should be concerned about students drinking behavior and determine what can be done to reduce problematic drinking.

\section{INTRODUCTION}

College students continue to be seriously injured or die as a result of drinking. Among college students and other 18 to 24 year olds, binge drinking is also known as high risk drinking, and in particular, incidents of driving while intoxicated (DWI) have increased since 1998. The number of students who reported DWI increased from 2.3 million students in 2000 to 2.8 million in $2010 .^{1}$ Another line of research examined how becoming intoxicated at a young age is linked to later drinking problems during the college years. ${ }^{1}$ The results showed that college students who first became intoxicated prior to age 19 were significantly more 
likely to be alcohol dependent and frequent heavy drinkers. These younger drinkers also were more likely to report driving after drinking, riding with a driver who was drinking or drunk, and sustaining injuries after drinking alcohol that required medical attention. ${ }^{1}$ Reports show that $82 \%$ of college students have tried alcohol at least once in their lifetime and $71 \%$ report they have been drunk. ${ }^{1}$ More importantly, perhaps, is the occurrence of binge drinking where $38 \%$ of college students reported binge drinking. ${ }^{1}$ Binge drinking was defined as having consumed five or more drinks in a row at least once in the twoweeks prior to completing the survey.

Although these statistics are alarming, the numbers are slowly coming down for college students. Trends in alcohol consumption among college students continue to slowly decline across all prevalence rates measured. From 1991 to 2010, annual consumption declined $11 \%$, monthly alcohol consumption has declined $13 \%$, and binge drinking among college students declined from $43 \%$ in 1991 to $37 \%$ in $2010 .{ }^{1}$ Alcohol is a part of Western society, and the majority of Americans enjoy alcoholic beverages. To pretend that young people will grow up to enter a world of alcohol abstinence is both unrealistic and irresponsible. Even religious groups strongly committed to alcohol abstinence are not very successful in maintaining it among their young people, the majority of whom drink. This is true even among students attending church supported schools. ${ }^{2}$ Alcohol consumption on many college campuses has evolved into a rite of passage. Traditions and beliefs handed down through generations of college drinkers serve to reinforce students' expectations that alcohol is a necessary component of social success. The role of alcohol in college life is evident in the advertising and sale of alcoholic beverages on or near campuses. This combination of social and environmental influences creates a culture of drinking that passively or actively promotes the use of alcohol.

A significant volume of research over the past ten years has focused on alcohol and drinking-related behaviors and to a lesser extent analyzed psychosocial factors. Very few studies focused on student knowledge of alcohol as a primary factor for study. The populations most frequently examined were traditional residential college and university student populations. Empirical data suggests that alcohol is still the number one drug of choice, and that a large proportion of college students drink. Drinking among college students has traditionally been a part of the college experience regardless of the legal status of their alcohol consumption. Of particular concern in much of the literature is the exhibition of underage drinking. Other issues of concern include quantity of alcohol consumed, binge drinking, drinking-related violent behavior, other drinking-related behaviors, and gender and ethnic differences. Of particular interest to this study is the knowledge versus behavior of health science and nursing (healthcare) students regarding alcohol consumption.

\section{LITERATURE REVIEW}

\section{Alcohol and the Body}

When alcohol is consumed, it passes from the stomach and intestines into the blood, a process referred to as absorption. A number of factors influence the absorption process, including the presence of food and the type of food in the gastrointestinal tract when alcohol is consumed. The rate at which alcohol is absorbed depends on how quickly the stomach empties its contents into the intestine. The higher the dietary fat content, the more time this emptying will require and the longer the process of absorption will take. One study found that subjects who drank alcohol after a meal that included fat, protein, and carbohydrates absorbed the alcohol about three times more slowly than when they consumed alcohol on an empty stomach. ${ }^{3}$ Alcohol is then metabolized by enzymes, which are body chemicals that break down other chemicals. In the liver, an enzyme called alcohol dehydrogenase (ADH) mediates the conversion of alcohol to acetaldehyde. Acetaldehyde is rapidly converted to acetate by other enzymes and is eventually metabolized to carbon dioxide and water. Alcohol also is metabolized in the liver by the enzyme cytochrome P450IIE1 (CYP2E1), which may be increased after chronic drinking. ${ }^{4}$ Most of the alcohol consumed is metabolized in the liver, but the small quantity that remains un-metabolized permits alcohol concentration to be measured in one's breath and urine.

The liver can metabolize only a certain amount of alcohol per hour, typically one standard drink, regardless of the amount that has been consumed. The rate of alcohol metabolism depends, in part, on the amount of metabolizing enzymes in the liver, which varies among individuals and appears to have genetic determinants. ${ }^{5}$ Women absorb and metabolize alcohol differently from men. Women have higher blood alcohol concentrations (BAC) after consuming the same amount of alcohol as men and are more susceptible to alcoholic liver disease, heart muscle damage, and brain damage. 6,7 The difference in BAC's between women and men has been attributed to women's smaller amount of body water, likened to dropping the same amount of alcohol into a smaller pail of water. An additional factor contributing to the difference in BAC's may be that women have lower activity of the alcohol metabolizing enzyme ADH in the stomach, causing a larger proportion of the ingested alcohol to reach the blood. The combination of these factors may render women more vulnerable than men to alcohol-induced liver and heart damage. ${ }^{8}$ In general, after the consumption of one standard drink, the amount of alcohol in the drinker's blood (blood alcohol concentration, or 
BAC) peaks within 30 to 45 minutes. A standard drink is defined as 12 ounces of beer, 5 ounces of wine, or 1.5 ounces of 80proof distilled spirits, about $1 / 2$ ounce of pure alcohol. Alcohol is metabolized more slowly than it is absorbed. Since the metabolism of alcohol is slow, consumption needs to be controlled to prevent accumulation in the body and intoxication.

\section{College Students Drinking}

Research consistently demonstrates that the majority of college students report consuming alcohol, many report drinking frequently, and a large proportion report engaging in heavy episodic or binge drinking, defined as four or more drinks in one sitting for women and five or more drinks in one sitting for men. Approximately four out of five of all college students report using alcohol at least once in a given year. ${ }^{9}$ Alcohol consumption among young men and women is a nation-wide occurrence, and heavy and problematic use is also widespread. A recent study of 71,189 undergraduate students from 134 colleges across the United States found that $71.8 \%$ of all students surveyed, $66 \%$ of whom were underage, reported consuming alcohol at least once in the 30 days prior to taking the survey. The same survey indicated that $55 \%$ of college students reported engaging in heavy episodic drinking, defined as consuming five or more drinks in one sitting, at least once in the preceding two weeks. ${ }^{10}$ Another national study $(n=14,138)$ indicated that of the students who reported engaging in binge drinking, $21.4 \%$ identified themselves as "occasional binge drinkers," defined as engaging in one to two binge drinking episodes in the previous two weeks, and $22.7 \%$ identified as "frequent binge drinkers," defined as three or more binge drinking episodes in the preceding two weeks. ${ }^{11}$ The problem of binge drinking among college students has persisted from 2000 to 2011, thus, a substantial portion of college students report engaging in heavy drinking. The highest prevalence of problem drinking is among young adults. ${ }^{1}$ In fact, over 20 years of research has consistently documented that in comparison to the general population, individuals between the ages of 18 and 24 are the heaviest drinkers and represent the greatest proportion of individuals with diagnosable alcohol-use disorders. ${ }^{12}$ In a large nationwide study, researchers found that approximately $25 \%$ of college students who reported drinking in the past year were considered abusers of alcohol or alcohol dependence in the past year. ${ }^{13}$ In a smaller study, other researchers found that in a sample of 306 undergraduate students, approximately $13 \%$ were alcohol abusers, and $11 \%$ met criteria for alcohol dependence within the past year. ${ }^{14} \mathrm{Clearl}$, alcohol use is a major health concern plaguing U.S. college campuses.

\section{Alcohol-Related Consequences}

An alarming finding from a recent analysis of epidemiological data available on U.S. college students indicated that 1,825 students lost their lives due to alcohol-related injuries, including traffic accident and other unintentional injuries. ${ }^{15}$ Unfortunately, heavy drinking endangers not only students who consume alcohol, but also other college students and members of the community at large. Approximately three out of four non-binge drinkers and abstainers (77\%) experience at least one secondhand effect of drinking. ${ }^{11}$ For example, in one survey, $30 \%$ of college students reported being assaulted or humiliated by an intoxicated peer. ${ }^{16}$ Additionally, nearly $60 \%$ of non-binge drinkers and abstainers reported experiencing an unwanted sexual advance by someone who was intoxicated. ${ }^{16}$ About 97,000 of college students experienced a sexual assault or date rape perpetrated by a college student under the influence of alcohol in 2001 alone, a number consistent with data reported over the past 10 years. ${ }^{17}$ Drinking and driving is another serious consequence of alcohol use that can affect drinking and non-drinking college students. Approximately 3.3 million college students or $28.9 \%$ of those surveyed drove under the influence of alcohol, and more than 3 million students or $38.9 \%$ of those surveyed rode as a passenger with a driver who had been drinking. ${ }^{15,17}$ Risky behavior associated with drinking puts many people in danger of serious injury or death. However, drinking and the negative consequences associated with consumption of alcohol have been regarded as the most preventable cause of morbidity and mortality among college students..$^{18}$ It is imperative that researchers continue investigating risk factors for heavy alcohol consumption and alcohol-related problems so that future intervention and prevention efforts can be tailored to help college students most in need. Reducing alcohol use among college students can have a positive impact on individual students' long term health and wellness as well as the entire campus community.

Research regarding drinking and college students is greatly varied. There have been many studies done on the health problems associated with drinking. Accordingly, Americans consume the largest amounts of alcohol between the ages of 18 to $25 . .^{19}$ This comes as no surprise as the ages of 18 to 25 coincides with the transition from high school into college. The researchers found that an estimated 30 percent of college students had consumed alcohol within the last month, and almost 70 percent of those drinkers report engaging in heavy drinking. Along with the consumption of alcohol, it was also found that of these students, 19.5 percent reported using marijuana, and 8.2 percent reported using other illicit drugs. Drinking rates have remained about the same for the past two decades. ${ }^{19}$ These studies show that over the last two decades, the use of alcohol has been common among college students with binge drinking particularly problematic increasing the likelihood of illness, injuries or death. 


\section{METHOD}

A descriptive exploratory study with survey methodology was conducted at twelve Midwest universities (see Table 4). The Institutional Review Board at the University of Central Missouri approved the study and its procedures. The researchers contacted faculty at the participating universities via email and telephone who then placed the link for the survey on Blackboard and WebCT. Faculty also made announcements in their classes encouraging students to participate in the study. The email consisted of an information letter and the questionnaire with the link to the online survey tool www.surveymonkey.com. The students gave consent to participate in the study electronically before they could start the survey. A convenient sample of 154 healthcare students (112 females, 40 males and 2-no gender identified) were recruited for the study. It was a non-probability, online convenience sample; participants were chosen on the criteria of being healthcare majors attending Midwestern universities.

A self reported 36 item questionnaire was adapted from the Student Alcohol Questionnaire. Permission was granted to use the questionnaire for this study from researchers at Indiana University. This questionnaire was used in several previous studies. ${ }^{20} \mathrm{In}$ addition to eliciting background information, the questionnaire assessed participants' knowledge and behaviors associated with drinking alcoholic beverages. Minor modifications were made to the background information section to reflect the present study. The participants provided background information about their age, gender, race, academic classification, and GPA. The participants' knowledge level of alcohol was measured using a 5-point Likert Scale, measuring the intensity of the respondents' knowledge ranging from one "strongly disagree" to five "strongly agree." The data was collected through a self-administered survey questionnaire with an introductory script placed on the first page of the link that explained the study purpose and invited students to participate. The informed consent form explained both the study and participants' rights. These rights included the option to not participate or stop at any time without any negative consequence. Those who participated in this study did so voluntarily and were offered no compensation.

The questionnaire consisted of three sections addressing knowledge, attitude, and alcohol consumption behavior. A sociodemographic profile also was included to collect information about gender, race, age, and year in school. The participant's behavior was defined in terms of type of alcoholic beverage consumed, how often, how many drinks, and where the drinking was taking place. The alcohol policy of six universities in this study does not allow the consumption of alcohol on campus residence halls for any student. This will have some effect on the responses, reducing the number of students who may have otherwise consumed alcohol in the dorms. The survey questionnaire administered was a slightly shortened version of the Student Alcohol Questionnaire used by researchers at Indiana University.

The reliabilities of the Quantity/Frequency Patterns, Problems Resulting from Drinking, Knowledge of Alcohol, and Attitudes Toward Drinking subscales were reported. The Spearman-Brown reliability coefficients of the subscales were $.84, .89, .85$, and .27 , respectively, in the Indiana study. The values of Cronbach alpha for the four subscales were $.86, .92$, .86, and .55 , respectively. For this present study, descriptive tests such as frequencies and percentages were analyzed using www.SurveyMonkey.com while Excel version 2007 was used to determine correlation, mean, and standard deviation. The correlation coefficient test was used as the measure for association. These tests were used to describe knowledge and drinking behavior associated with college students drinking.

\section{RESULTS}

\section{Characteristics of Respondents}

The respondents $(n=154)$ were undergraduates healthcare students, $72.7 \%(n=112)$ were female, $26.0 \%(n=40)$ were male, and $1.3 \%(n=2)$ had no response. The typical participant was female, Caucasian, and 18 to 23 years old. Further descriptive items are listed in Table 1. 
Table 1. Demographics of the Participants

\begin{tabular}{|c|c|c|}
\hline & $\mathrm{N}$ & Percent (\%) \\
\hline \multicolumn{3}{|l|}{ Gender } \\
\hline Female & 112 & 72.7 \\
\hline Male & 40 & 26.0 \\
\hline No Response & 2 & 1.3 \\
\hline \multicolumn{3}{|l|}{ Ethnicity } \\
\hline Caucasian & 126 & 81.9 \\
\hline African American & 20 & 13.0 \\
\hline Hispanic & 3 & 1.9 \\
\hline Asian & 3 & 1.9 \\
\hline Other & 2 & 1.3 \\
\hline \multicolumn{3}{|l|}{ Age } \\
\hline $18-20$ & 68 & 44.2 \\
\hline $21-23$ & 46 & 29.9 \\
\hline $24-30$ & 24 & 15.6 \\
\hline $31-35$ & 6 & 3.9 \\
\hline $35+$ & 10 & 6.5 \\
\hline \multicolumn{3}{|l|}{ Class } \\
\hline Freshman & 25 & 16.2 \\
\hline Sophomore & 41 & 26.6 \\
\hline Junior & 27 & 17.5 \\
\hline Senior & 60 & 39.0 \\
\hline No Response & 1 & 0.7 \\
\hline
\end{tabular}

Respondents' knowledge about alcohol was very good with the mean score of 3.5 or higher on factual statements about alcohol with standard deviation of 1.3 or less as shown in Table 2. Using a 1-5 points Likert scale, a mean score of less than 2.5 will indicate limited knowledge, 2.5 to 3.5 will indicate fair knowledge, and above 3.5 will indicate very good knowledge. The researchers used the following factual statements means to determine the respondents' knowledge about alcohol "In the USA, one drink is usually considered to be 12 ounces of beer, 5 ounces of wine, or $1 \frac{1}{2}$ ounces of spirits (hard liquor such as gin or whiskey) i.e.1/2 ounce of pure alcohol." "Alcohol consumption risks far outweigh the benefits." "Table wine; red, white, \& rose contains from 2-12\% alcohol by volume." "Beer contains from 2-6\% alcohol by volume." "Blood Alcohol Content can be $0.10 \%$ or $0.08 \%$ in different states." The means were $M=4.0, M=4.0, M=3.7, M=3.7$ and $M=3.6$ respectively indicating very good knowledge about alcohol by healthcare students. Although in previous studies overall knowledge for residential college students was generally low, this study indicated that healthcare college students' knowledge regarding alcohol was higher than alcohol knowledge of students from traditional colleges. ${ }^{21}$ 
Table 2. Knowledge about Alcohol

\begin{tabular}{|c|c|c|c|}
\hline & $\mathbf{N}$ & Mean & SD \\
\hline $\begin{array}{l}\text { In the USA, one drink is usually considered to be } 12 \text { ounces of beer, } 5 \text { ounces of wine, } \\
\text { or } 1 \frac{1}{2} \text { ounces of spirits (hard liquor such as gin or whiskey) i.e. } 1 / 2 \text { ounce of pure } \\
\text { alcohol. }\end{array}$ & 151 & 4.0 & 1.0 \\
\hline $\begin{array}{l}\text { What you drink (beer, wine or liquor) doesn't seem to be nearly as important as how } \\
\text { much you drink. }\end{array}$ & 154 & 2.8 & 1.3 \\
\hline Alcohol increases the risk of a woman developing breast cancer. & 151 & 3.0 & 1.0 \\
\hline $\begin{array}{l}\text { If there is a history of alcoholism in your family you should not drink alcoholic } \\
\text { beverages. }\end{array}$ & 154 & 3.3 & 1.1 \\
\hline $\begin{array}{l}\text { Alcohol is a factor in the four leading causes of death among persons ages } 10 \text { to } 24 \text { in } \\
\text { the USA. }\end{array}$ & 154 & 3.9 & 0.9 \\
\hline Alcohol consumption risks far outweigh the benefits. & 153 & 4.0 & 1.0 \\
\hline Alcohol was used for centuries as a medicine in childbirth, for sedation and surgery. & 153 & 3.5 & $\mathbf{1 , 0}$ \\
\hline Table wine; red, white, \& rose contains from $2-12 \%$ alcohol by volume. & 153 & 3.7 & 0.7 \\
\hline Beer contains from $2-6 \%$ alcohol by volume. & 154 & 3.7 & 0.9 \\
\hline Blood Alcohol Content can be $0.10 \%$ or $0.08 \%$ in different states. & 154 & 3.6 & 0.9 \\
\hline The most commonly drunk alcoholic beverage in the USA is wine. & 152 & 2.5 & 0.9 \\
\hline Eating protein and fatty foods will slow down the absorption of alcohol in the body. & 154 & 3.3 & 1.1 \\
\hline Taking a cold shower or drinking coffee can be an effective way of sobering up. & 153 & 2.3 & 1.1 \\
\hline $\begin{array}{l}\text { Moderate alcohol consumption can reduce the risk of cardiovascular and other } \\
\text { diseases. }\end{array}$ & 154 & 3.2 & 0.9 \\
\hline An alcoholic drink before a meal can improve digestion. & 150 & 2.8 & 0.9 \\
\hline An alcoholic drink can offer a soothing respite at the end of a stressful day. & 154 & 3.4 & $\mathbf{1 . 0}$ \\
\hline The occasional alcoholic drink with friends can be a social tonic. & 152 & 3.8 & 0.9 \\
\hline $\begin{array}{l}\text { Moderate alcohol consumption can have positive physical and emotional effects that } \\
\text { may contribute to better health and well-being. }\end{array}$ & 154 & 3.0 & $\mathbf{1 . 0}$ \\
\hline $\begin{array}{l}\text { Many people drink for social acceptance, because of peer group pressures, and to gain } \\
\text { adult status when turning age } 21 \text {. }\end{array}$ & 153 & 4.1 & 0.8 \\
\hline Alcoholic beverages does provide weight increasing calories. & 153 & 4.0 & 1.1 \\
\hline
\end{tabular}

\section{Drinking Behaviors}

The drinking behavior section assesses an individual's typical quantity and frequency of alcohol consumption. A host of quantity and frequency measures can be calculated from responses. In the present study, $84.4 \%(n=130)$ were drinkers while $15.6 \%$ $(n=24)$ were non-drinkers. Almost $54 \%(53.8 \%, n=70)$ of the students who drink alcoholic beverages classify themselves as 
occasional drinkers, $22.3 \%(n=29)$ as light drinkers, $20.8 \%(n=27)$ as moderate drinkers, and 3.1\% $(n=4)$ as heavy drinkers. The typical drink of choice preference included beer $35.7 \%(n=46)$, wine $10.9 \%(n=14)$, hard liquor $29.5 \%$ ( $n=38)$ and fruit flavored coolers, hard lemonade etc. $24.0 \%(n=31)$, see Table 3.

Table 3. Drinking Behaviors

\begin{tabular}{|c|c|c|}
\hline & $\begin{array}{l}\text { Response } \\
\text { Percent }\end{array}$ & $\begin{array}{c}\text { Response } \\
\text { Count } \\
\mathrm{N}=130\end{array}$ \\
\hline \multicolumn{3}{|c|}{ If you drink alcoholic beverages, how would you classify yourself? } \\
\hline Occasional Drinker & $53.8 \%$ & 70 \\
\hline Light Drinker & $22.3 \%$ & 29 \\
\hline Moderate Drinker & $20.8 \%$ & 27 \\
\hline Heavy Drinker & $3.1 \%$ & 4 \\
\hline \multicolumn{3}{|c|}{ If you drink alcoholic beverages, what do you typically drink? } \\
\hline Beer & $35.7 \%$ & 47 \\
\hline Wine & $10.9 \%$ & 14 \\
\hline Hare Liquor & $29.5 \%$ & 38 \\
\hline Fruit flavored coolers, hard lemonade, etc. & $24.0 \%$ & 31 \\
\hline \multicolumn{3}{|l|}{ How often do you have a drink of alcohol beverage? } \\
\hline 1 time a week & $8.5 \%$ & 11 \\
\hline 2-3 times a week & $22.3 \%$ & 29 \\
\hline 4-6 times a week & $2.3 \%$ & 3 \\
\hline Daily & $0.8 \%$ & 1 \\
\hline Weekends only & $12.3 \%$ & 16 \\
\hline 2 times a month & $12.3 \%$ & 16 \\
\hline 4-6 times a month & $9.2 \%$ & 12 \\
\hline Occasionally & $32.3 \%$ & 42 \\
\hline \multicolumn{3}{|c|}{$\begin{array}{l}\text { How many standard drinks containing alcohol do you have on a typical day when } \\
\text { drinking? }\end{array}$} \\
\hline 1 or 2 & $42.3 \%$ & 55 \\
\hline 3 or 4 & $27.7 \%$ & 36 \\
\hline 5 or 6 & $17.7 \%$ & 23 \\
\hline 7 or 9 & $7.7 \%$ & 10 \\
\hline 10 or more & $4.6 \%$ & 6 \\
\hline \multicolumn{3}{|c|}{ How often do you have six or more drinks on one occasion? } \\
\hline Never & $44.5 \%$ & 58 \\
\hline Weekends & $24.2 \%$ & 31 \\
\hline 1 or 2 Monthly & $30.5 \%$ & 40 \\
\hline Daily or almost daily & $0.8 \%$ & 1 \\
\hline \multicolumn{3}{|c|}{$\begin{array}{l}\text { During the past year, how often have you found that you were not able to stop } \\
\text { drinking once you had started? }\end{array}$} \\
\hline Never & $84.0 \%$ & 109 \\
\hline Weekends & $8.4 \%$ & 11 \\
\hline 1 or 2 Monthly & $6.9 \%$ & 9 \\
\hline Daily or almost daily & $0.8 \%$ & 1 \\
\hline \multicolumn{3}{|l|}{ Where do you consume alcohol mostly? } \\
\hline My Apartment commons area & $13.1 \%$ & 17 \\
\hline My Bedroom & $0.8 \%$ & 1 \\
\hline Night Clubs & $4.6 \%$ & 6 \\
\hline Bars & $20.0 \%$ & 26 \\
\hline House Parties & $39.2 \%$ & 51 \\
\hline Friend's apartment & $9.2 \%$ & 12 \\
\hline Dormitory & $0.8 \%$ & 1 \\
\hline Other (write in) & $12.3 \%$ & 16 \\
\hline
\end{tabular}


In this study, $12.3 \%$ ( $n=16$ ) of participants reported drinking on weekends only, and $32.3 \%$ ( $n=42)$ reported drinking occasionally. Overall, a much smaller percentage of the respondents in this study reported drinking alcohol at least monthly in comparison to the general college population as has been reported in earlier literature. For example, previous studies have reported that 65 to $70 \%$ of students report drinking on a monthly basis. 12,22 Similarly, $67 \%$ of the respondents in this study reported drinking alcohol at least one time per month. Participants were also asked to estimate the number of alcoholic beverages they consumed on a typical occasion when they drank alcohol. A high frequency of this sample of students $(30 \%)$ reported consuming five or more alcoholic beverages per occasion. Three to four alcoholic beverages were consumed by $27.7 \%$ of this sample. Overall, these data suggest that $30 \%$ of the respondents of undergraduate healthcare students engage in high risk alcohol consumption as defined by five or more alcoholic beverages on a typical drinking occasion. Though it is alarming, the data imply that less students in this sample engaged in high risk alcohol consumption more frequently than in the general population of college students, in which this behavior has been reported to be between 40 to $44 \% .{ }^{12,15}$

The Pearson correlation coefficients were calculated using knowledge about alcoholic beverages with "How many standard drinks containing alcohol do you have on a typical day when drinking?"; "How often do you have a drink of alcohol beverage?"; and "How often do you have five or more drinks on one occasion?" The results respectively were $r=0.17, p=0.0167$, which implies that more knowledge was associated with more drinking; $r=-0.12, p=0.0125$, which implies that more knowledge was associated with drinking less often; and $r=0.19, p=0.0125$, which implies that more knowledge was associated with excessive drinking. The three measures were weakly correlated meaning that drinking behavior was weakly associated with knowledge. The results suggest that the correlation can be used with a reasonable degree of confidence, bearing in mind the tendency for heavy drinkers to underestimate consumption and drinking behavior. Relationships between binge drinking specificity and alcohol consumption support the idea that the criteria for binge drinkers should be based on patterns of drinking rather than alcohol consumption. The total amount of alcohol drunk may not provide an accurate description of binge drinking, as it is proposed that patterns of binge drinking behavior, rather than quantity of alcohol consumed, increases the degree of alcohol dependence. As the results revealed, beer and spirits would appear to be the beverage of choice for binge drinkers among students. There was a high proportion of female in the population sample, so it was surprising that wine was not the drink of choice. Overall, there was significantly less wine drunk than beer and spirits. Beer and spirits made up the majority of alcohol consumed.

\section{DISCUSSION}

The results of this study showed that healthcare college students' knowledge regarding alcohol was very good based on the mean scores of factual statements using a 1-5 point Likert scale. The researchers used the following factual statements means to determine the respondents' knowledge about alcohol "In the USA, one drink is usually considered to be 12 ounces of beer, 5 ounces of wine, or $1 \frac{1}{2}$ ounces of spirits (hard liquor such as gin or whiskey) i.e. $1 / 2$ ounce of pure alcohol." "Alcohol consumption risks far outweigh the benefits." "Table wine; red, white, \& rose contains from 2-12\% alcohol by volume." "Beer contains from 2$6 \%$ alcohol by volume." "Blood Alcohol Content can be $0.10 \%$ or $0.08 \%$ in different states." Using a $1-5$ points Likert scale, a mean score of less than 2.5 will indicate limited knowledge, 2.5 to 3.5 will indicate fair knowledge and above 3.5 will indicate very good knowledge. The means were $M=4.0, M=4.0, M=3.7, M=3.7$ and $M=3.6$ respectively indicating very good knowledge about alcohol by healthcare students. A popular alcohol consumption style among college students is binge drinking, considered a rite of passage by many college students. Binge drinking occurs when a person has five or more drinks consistently which is one of the main causes of alcohol poisoning. There is no surprise that $30 \%$ of the respondents in this study participated in this behavior. Healthcare professionals represent the main group of health workers with an important role in the prevention, early detection and treatment of alcoholism. This suggests that greater efforts should be made to improve alcohol education at the collegiate level, especially in the preparation of healthcare students. The study also found there to be little to no association between alcohol knowledge and drinking behavior. Binge drinking was identified as a behavior with many negative physical and emotional health effects. These young people are potentially harming themselves without knowing it. The prevention and risks of this action should be at the fore front of healthcare students. Health care professionals in the community and the hospital setting need to be creating strategies for prevention of binge drinking in the population while promoting healthy practices that will provide the young people with good foundations to build their emotional and physical wellness. There is no better place for healthcare students to start exhibiting responsible alcohol behavior than in college.

According to the Center for Disease Control and Prevention binge drinking is highest among people in the age range 18-24.23 When one consumes alcohol, the liver has to metabolize or drain the alcohol and other toxins from the blood. Alcohol is absorbed much faster than food and reaches the bloodstream quickly. The liver can only process one standard drink of alcohol per hour. Consuming large amounts of alcohol in a short period of time can cause alcohol poisoning. By drinking too much too quickly, it affects the breathing, heart rate, and gag reflexes, and can lead to coma or death. The faster one drinks, the higher the blood alcohol concentration becomes, causing the level to rise at an extreme rate. Rapid drinking can bring one's Blood Alcohol 
Concentration (BAC) so high that the individual's mental and physical functions become negatively affected. After binge drinking, the heart's rhythm may become irregular, and one may also suffer shortness of breath and choke. If the BAC is high enough, some important physical functions can stop working and the person can lose consciousness, thus affecting their health. The fact that $30 \%$ of the respondents of this study participated in binge drinking means that $70 \%$ of the respondents were not drinking in excess. Moderate alcohol consumption can have positive physical and emotional effects that may contribute to better health and well being. It is now an established medical fact that the moderate consumption of beer, wine, or distilled spirits improves health and longevity. Both beer and liquor tend to confer the same health benefits as red wine; the benefit is found in the alcohol rather than in a specific beverage.

Alcohol abusers put a heavy burden on the medical care system. It costs the health care system more than half a million dollars in blackout-related emergency room visits each year at an average large university. ${ }^{24}$ Forty-four percent of college students engage in binge drinking at one time or another, previous research indicates. The researchers surveyed nearly a thousand students at five universities, four in the U.S. and one in Canada. The students were all identified as problem drinkers and about half had experienced an alcohol-induced blackout in the year preceding the study. During the two-year study, 30 percent of the men and 27 percent of the women visited the emergency department at least once, some with major injuries like broken bones and head or brain trauma. Of the 404 emergency department visits reported by 954 participants in the study, about one in eight were associated with blackout drinking. ${ }^{22}$ The problems associated with binge drinking are more costly than originally thought; nationwide, the costs associated with excessive drinking and hospitalization exceeds more than $\$ 750$ million per year. ${ }^{23}$

Statistics show that more than ten million 12 to 20 -year-olds currently drink, and of that number, roughly seven million are binge drinkers. The highest rates of hospitalizations for binge drinking occurred in the Midwest and Northeast. The lowest rate was in the South with the West falling in between. Males are more likely than females to drink excessively; Native Americans, mixedrace persons, and whites are also more likely to drink too much compared to Hispanics and Asian/Pacific Islanders who had the lowest rate in this category. More hospitalizations were for injury and less than one percent of those admitted died. Those deaths on average involved males 18-21 years old. 25

The findings in the present study are especially pertinent now as thousands of college students' flock to Florida, Texas, Cancun, Bahamas, and Jamaica for spring break. The problem students run into on spring break is that drinking becomes fun and games, students load up on alcohol very, very quickly, and that, by definition, is binge drinking. College student drinking is the cause of many problems; around 1800 students die per year, nearly 600,000 are injured, almost 700,000 are assaulted, and 97,000 are victims of sexual assault. ${ }^{1}$ These are only a small number of drinking's effects; many more are affected in other ways not listed. Students who binge drink are more likely to experience a wide range of problems, including academic difficulties, social conflict, risky sexual behavior, risky driving behavior, vandalism, injury, and alcohol overdose. Binge drinkers were also more likely to engage in other high risk behaviors such as tobacco and illicit drug use. Students who binge drink frequently were most likely to experience these problems. ${ }^{26}$

In addition to the harm drinkers cause for themselves, the researchers drew attention to the problems that drinkers cause for others on and around campus. The "secondhand" effects of alcohol use, similar to the concept of secondhand smoke, helped people understand that student drinking is harmful to the larger campus community. These problems include drinking-related behavior that is disruptive to studying and sleep, vandalism, and physical and sexual assaults. The five/four drink binge measure is a good indicator of who will experience alcohol-related problems, and more importantly, captures most students who actually experience problems, something measures with higher drink thresholds fail to do. Binge drinkers account for the vast majority of unintentional injuries, vandalism, and disorderly behavior on campus. The researchers found that at 18 heavy-drinking U.S. campuses, students' alcohol habits showed little change over a dozen years. In 1993, 58 percent of students reported binge drinking in the past two weeks; in 2005, 56 percent said the same. And although 28 percent of students in 1993 said they frequently binged, that figure was 32 percent in 2005. Along with the persistently high levels of binge drinking, schools showed little change in the number of students who reported any drinking: 88.5 percent in 1993, and 86 percent in 2005. Nor was there progress in the behaviors that often go hand-in-hand with problem drinking, like physical injuries, unprotected sex, and drunk driving. In 1993, 37 percent of students said they had driven after drinking, and in 2005, the figure was the same.

Recent studies suggest that students claim to practice responsible drinking, but research shows that they see the term differently than the standardized definition. They do not associate this term with consuming a set number of drinks; instead, the majority considers responsible behavior to be designating a safe driver, relying on one individual so that others may drink in excess. Students need to realize that responsible drinking refers to their own behavior; it does not mean placing all responsibility upon another person. Colleges must continue to make an ongoing effort to educate students about responsible drinking from a health, safety, and legal viewpoint and students who choose to drink must accept responsibility to do so responsibly. 
In previous studies, overall knowledge for residential college students was generally low, while the present study indicated that healthcare college students' knowledge regarding alcohol was higher than alcohol knowledge of students from traditional colleges. ${ }^{21}$ The present study results closely parallel those of 1993 where 28 percent of the respondents binged, and 2005 where 32 percent participated in this behavior. In the present study, 30 percent of the respondents binged. The number of students who reported any drinking in 1993 and 2005 was steady at about 86 percent, and the result of the present study was basically the same at 85.5 percent. Overall, it can be inferred from the present study that the healthcare students were more knowledgeable about alcohol than students who participated in studies during 1993 and 2005, but these healthcare students drinking behavior was similar to those of previous studies where about one third of the respondents binged.

\section{CONCLUSION}

The results of this study show that the majority of students had very good knowledge about alcohol, but that tertiary education healthcare students have relatively high levels of risky alcohol consumption with $30 \%$ of the respondents involved in binge drinking. This knowledge was not associated with a lower likelihood of risky alcohol consumption. The Pearson correlation coefficients were calculated using knowledge about alcoholic beverages with "How many standard drinks containing alcohol do you have on a typical day when drinking?"; "How often do you have a drink of alcohol beverage?"; and "How often do you have five or more drinks on one occasion?" The results revealed weak associations between knowledge of alcohol and drinking behavior. There is a need for further research on the links between knowledge and drinking behavior. With approximately $50 \%$ of young people aged between 18 and 24 in vocational or higher education, interventions in these institutions have the potential to play a substantial role in reducing risky drinking behavior among this age group. Such interventions should aim to target the negative aspects of binge drinking, improve behavior towards alcohol, promote more effective means of coping with psychological distress, and improve help-seeking for alcohol problems. Research suggests that peer influences are based more on what we think others believe and do than on the real beliefs and actions. ${ }^{27}$ Social norms initiatives have been demonstrated to be effective in reducing alcohol use on college campuses by changing the perceived norms related to alcohol use. ${ }^{28}$ Binge drinking, a common pattern of excessive alcohol use, has been deemed the most serious public health issue on college campuses by the United States Surgeon General. Therefore, the need for an effective anti-binge drinking campaign targeted to college students has become crucial.

Table 4. 12 Midwest Universities Health \& Nursing Students Participating in this Study

\begin{tabular}{|l|l|}
\hline University of Central Missouri, MO & Southeast Missouri State University, MO \\
\hline Missouri State University, MO & Missouri Western State University, MO \\
\hline St. Louis University, MO & Pittsburg State University, KS \\
\hline Wichita State University, KS & University of Central Arkansas, AR \\
\hline Arkansas Technical University, AR & Fort Hays State University, KS \\
\hline University of Evansville, IN & Arkansas State University, AR \\
\hline
\end{tabular}

\section{REFERENCES}

1. National Institute on Alcohol Abuse and Alcoholism. (2010). College drinking: a snapshot of annual high-risk college drinking consequences. Retrieved from http://www.collegedrinkingprevention.gov/statssummaries/snapshot.aspx. Accessed July 20, 2012.

2. Hanson J. Preventing Alcohol Abuse: Alcohol, Culture, and Control. Westport, CT: Praeger, 1995; pp. 45-50.

3. Jones AW, Jonsson KA. Food-induced lowering of blood-ethanol profiles and increased rate of elimination immediately after a meal. Journal of Forensic Sciences. 1994;39(4):1084-93. [PMID 8064267]

4. Lieber CS. Relationships between nutrition, alcohol use, and liver disease. Alcohol Research \& Health, 2003;27(3):220-231. [PMID 15535450]

5. Molinoff PB, Ruddon RW, eds. Goodman and Gillman's The Pharmacological Basis of Therapeutics. 9th ed. New York: McGraw-Hill, 1996; pp. 3-27.

6. Urbano-Márquez A, Estruch R, Fernández-Solá J, Nicolás JM, Paré JC, Rubin E. The greater risk of alcoholic cardiomyopathy and myopathy in women compared with men. JAMA. 1995;274(2):149-54. [PMID 7596003]

7. Nixon SJ. Cognitive deficits in alcoholic women. Alcohol Health \& Research World. 1994;18(3):228-32.

8. Frezza M, di Padova C, Pozzato G, Terpin M, Baroana E, Lieber CS. High blood alcohol levels in women: The role of decreased gastric alcohol dehydrogenase activity and first-pass metabolism. The New England Journal of Medicine,1990;322(2):95-99. [PMID 2248624] 
9. Johnston LD, O'Malley PM, Bachman JG, Schulenberg JE. Monitoring the Future national results on adolescent drug use: Overview of key findings, 2004. (NIH Publication No. 05-5726). Bethesda, MD: National Institution Drug Abuse 2005.

10. Core Institute. American campuses: $2006-2008$ statistics on alcohol and other drug use. Carbondale, IL: Core Institute, Southern Illinois University; 2010. Retrieved from: http://www.core.siuc.edu/. Accessed March 4, 2012.

11. Wechsler H, Lee JE, Kuo M, Lee H. College binge drinking in the 1990s: A continuing problem. Journal of American College Health. 2000;48(5):199-210. [PMID 10778020]

12. O'Malley PM, Johnston LD. Epidemiology of alcohol and other drug use among American college students. Journal of Studies on Alcohol. 2002;63(Suppl. 14):23-39. [PMID 12022728]

13. Dawson DA, Grant BF, Stinson FS, Chou PS. Another look at heavy episodic drinking and alcohol use disorders among college and noncollege youth. Journal of Studies on Alcohol. 2004;65(4):477-88. [PMID 15378804]

14. Clements R. Prevalence of alcohol-use disorders and alcohol-related problems in a college student sample. Journal of American College Health. 1999;48(3):111-18. [PMID 10584445]

15. Hingson RW, Zha W, Weitzman ER. Magnitude of and trends in alcohol related mortality and morbidity among U.S. college students ages 18-24, 1998-2005. (Report). Journal of Studies on Alcohol and Drugs. 2009;70(Suppl.16):12-20. [PMID 19538908]

16. Wechsler H, Lee JE, Kuo M, Seibring M, Nelson TF, Lee H. Trends in college binge drinking during a period of increased prevention efforts. Findings from 4 Harvard School of Public Health College Alcohol Study surveys: 1993-

2001. Journal of American College Health. 2002;50(5):203-17. [PMID 11990979]

17. Hingson R, Heeren T, Winter M, Wechsler H. Magnitude of alcohol-related mortality and morbidity among U.S. college students ages 18-24: changes from 1998 to 2001. Annual Review of Public Health. 2005;26:259-79. [PMID 15760289]

18. Wechsler H, Dowdall GW, Davenport A, Castillo S. Correlates of college student binge drinking. American Journal of Public Health. 1995;85(7):921-6. [PMID 7604914]

19. Yusko DA, Buckman JF, White HR, Pandina RJ. Alcohol, tobacco, illicit drugs, and performance enhancers: A comparison use by college student athletes and nonathletes. Journal of American College Health. 2008;57(3):281-90. [PMID 18980883]

20. Professor Ruth Clifford Engs. Alcohol Research and Health History. Retrieved from http://www.indiana.edu/ engs. Accessed February 25, 2012.

21. Engs RC, Hanson DJ. The Student Alcohol Questionnaire: An Updated Reliability of the Drinking Patterns, Problems, Knowledge and Attitude Subscales. Psychological Reports. 1994;74(1):12-14. [PMID 8153201]

22. American College Health Association. American College Health Association National College Health Assessment spring 2006 reference group data report (abridged). Journal of American College Health. 2007;55(4):195-206. [PMID 17319325]

23. Center for Disease Control and Prevention Health Report 2010. Retrieved from http://www.cdc.gov/. Accessed March 10, 2012.

24. Mundt PM, Zakletskaia LI. Prevention For College Students Who Suffer Alcohol-Induced Blackouts Could Deter High-Cost Emergency Department Visits. Journal of Health Affairs. 2012;31(4):863-70.

25. Johnston LD, O'Malley PM, Bachman JG, Schulenberg JE. Monitoring the Future: National Results on Adolescent Drug Use: Overview of Key Findings, 2010. Ann Arbor: Institute for Social Research, 2011; The University of Michigan.

26. Nelson TF, Xuan Z, Lee H, Weitzman ER, Wechsler H. Persistence of Heavy Drinking and Ensuing Consequences at Heavy Drinking Colleges. Journal of Studies on Alcohol and Drugs. 2009;70(5):726-34. [PMID 19737497]

27. Berkowitz A. The social norms approach: theory, research, and annotated bibliography from http://www.alanberkowitz.com/articles/social_norms.pdf 2004.

28. Perkins HW. The social norms approach to preventing school and college age substance abuse: A handbook for educators, counselors, and clinicians (1st ed.), 2003;San Francisco: Jossey-Bass. 